\title{
Benefit from the inclusion of self-treatment guidelines to a self-management programme for adults with asthma
}

\author{
J.J. Klein*, J. van der Palen*, S.M. Uil*, G.A. Zielhuis ${ }^{\Uparrow}$, E.R. Seydel ${ }^{+}$, C.L.A. van Herwaarden ${ }^{\#}$
}

Benefit from the inclusion of self-treatment guidelines to a self-management programme for adults with asthma. J.J. Klein, J. van der Palen, S.M. Uil, G.A. Zielhuis, E.R. Seydel, C.L.A. van Herwaarden. (C) ERS Journals Ltd 2001.

ABSTRACT: This study assessed the long-term efficacy of adding self-treatment guidelines to a self-management programme for adults with asthma.

In this prospective randomized controlled trial, 245 patients with stable, moderate to severe asthma were included. They were randomized into a self-treatment group (group S) and a control group (group C). Both groups received self-management education. Additionally, group $S$ received self-treatment guidelines based on peak expiratory flow (PEF) and symptoms. Outcome parameters included: asthma symptoms, quality of life, pulmonary function, and exacerbation rate. The 2-yr study was completed by 174 patients.

Both groups showed an improvement in the quality of life of 7\%. PEF variability decreased by $32 \%$ and $29 \%$, and the number of outpatient visits by $25 \%$ and $18 \%$ in groups $\mathrm{S}$ and $\mathrm{C}$, respectively. No significant differences in these parameters were found between the two groups. After $1 \mathrm{yr}$, patients in both groups perceived better control of asthma and had more self-confidence regarding their asthma. The latter improvements were significantly greater in group $\mathbf{S}$ as compared to group $\mathrm{C}$. There were no other differences in outcome parameters between the groups.

Individual self-treatment guidelines for exacerbations on top of a general selfmanagement programme does not seem to be of additional benefit in terms of improvements in the clinical outcome of asthma. However, patients in the self-treatment group had better scores in subjective outcome measures such as perceived control of asthma and self-confidence than patients in the control group. Eur Respir J 2001; 17: 386-394.
*Dept of Pulmonary Medicine, Medisch Spectrum Twente, Enschede, ${ }^{\#}$ Depts of Pulmonary Medicine and 'Epidemiology, Dekkerswald, University of Nijmegen and ${ }^{+}$Dept of Psychology, University of Twente, Enschede, the Netherlands.

Correspondence: J.J. Klein, Medisch Spectrum Twente, Afdeling Longziekten, Postbus 50000, $7500 \mathrm{KA}$ Enschede, the Netherlands Fax: 310534872638

Keywords: Asthma

patient education

self-management

self-treatment

Received: February 32000

Accepted after revision September 19 2000

This study was funded by the Netherlands Asthma Foundation (Grant 94-52), GlaxoWellcome, the "Stichting Astmabestrijding", and Amicon Health Care Insurance Fund.
During the 1980s, the mortality and morbidity of asthma rose [1-3], which led to concerns about the adequacy of the treatment of asthma [4]. For this reason national and international guidelines on the management of asthma were developed. Today, these guidelines stress the importance of self-management $[5,6]$.

Most self-management programmes, which include guidelines for self-treatment of exacerbations, have been demonstrated to improve health-related outcomes in patients with asthma [7-17].

The term "self-management" refers to a behaviour based on appropriate knowledge about asthma and its provoking factors, compliance with inhaled medication, self-monitoring of changes in severity of the disease, recognition of symptoms, adequate inhalation technique, and correct use of a peak flow meter. "Self-treatment" refers to a specific component of selfmanagement defined as the self-adjustment of the medical therapy according to changes in disease severity, based on a set of written guidelines.

The guidelines for self-treatment are intended to be an important part of self-management programmes. However, little is known about the net effects of these guidelines, because studies on self-management have evaluated these programmes as a whole, or compared peak expiratory flow (PEF) and symptom self-treatment plans [7-17]. Therefore, it is difficult to assess the added benefit and safety of self-treatment guidelines to a self-management programme.

For this reason a study to assess the effects of selftreatment of exacerbations in adults with asthma on pulmonary function, quality of life, morbidity, asthma symptoms, and perceived control of asthma and selfconfidence regarding asthma was designed.

Originally, this study was designed with a follow-up of $1 \mathrm{yr}$. However, during this first year it was realised that the long-term effects ( $>12$ months) of a selfmanagement programme should also be studied, since asthma in adults is a chronic disease.

The objective of this study was to assess the longterm effects and safety of adding self-treatment guidelines to a self-management programme for adults with moderate to severe asthma who were well-controlled and already on a relatively high dose of inhaled corticosteroids at the start of the study.

\section{Methods}

Study design

The study was a single centre, single blinded, randomized, parallel group, prospective trial and it 
was approved by the hospital's ethics committee. All subjects signed the informed consent form.

\section{Study population}

The study population was recruited August 1995April 1996. After a search of the database of the outpatient clinic of the Department of Pulmonary Medicine of a teaching hospital $(1,100$ beds $)$ in Enschede, the Netherlands, 485 patients with the diagnosis of asthma were identified. They were all invited, by mail, to participate in a self-management trial, and within 10 days they were contacted by telephone, 157 subjects $(32 \%)$ refused to participate. The remaining 328 patients were further examined in the pulmonary function laboratory twice within 10 days.

\section{Inclusion and exclusion criteria}

The inclusion criteria were: between the ages of $18-65$, a continuous use of inhaled steroids (at least $200 \mu \mathrm{g} \cdot \mathrm{day}^{-1}$ by metered dose inhaler (MDI) or $400 \mu \mathrm{g} \cdot \mathrm{day}^{-1}$ by dry powder inhaler) for at least three months, in a stable phase of their disease during the last six weeks, defined by no use of short courses of oral steroids or no increase of a maintenance dose of oral steroids, and ability to speak and read the Dutch language.

The diagnosis of asthma was confirmed at baseline by a reversibility in forced expiratory volume in one second (FEV1) of $\geqslant 15 \%$ of the initial value, or $>9 \%$ of the predicted value after inhalation of $400 \mu \mathrm{g}$ salbutamol by MDI [18] or a provocative concentration (PC20) of histamine causing a $20 \%$ fall in FEV1 of $\leqslant 8 \mathrm{mg} \cdot \mathrm{mL}^{-1}[19]$. Subjects with a PC20 histamine $8-16 \mathrm{mg} \cdot \mathrm{mL}^{-1}$ with documented reversibility in FEV1 in the previous 3 yrs were also included. If the pre-bronchodilator FEV1 was $<90 \%$ of the best personal value measured in the pulmonary function laboratory during the last 3 yrs, patients were considered to be unstable. These patients were asked to double the dose of their inhaled steroids for 2 weeks to optimize lung function. After these 2 weeks, prebronchodilator FEV1 was repeated. The exclusion criteria were serious medical or psychiatric comorbidity. After the two inclusion visits, $83(25 \%)$ of the 328 patients were excluded, mostly because FEV1 reversibility was $<15 \%$ of the initial value or $9 \%$ of predicted. The remaining 245 subjects were randomized into a self-treatment group (group S) and control group (group C) by a closed envelope method.

Before the end of the first year of the study, patients were asked to participate for a second year. Sixty-four $(27 \%)$ of the remaining 238 patients (seven patients were lost to follow-up in the first year) refused to participate, so 174 patients continued for a second year of follow-up.

\section{Interventions}

At the first visit, skin-prick tests [20] and spirometry before and after salbutamol inhalation [18] were carried out. A wet type spirometer (Pulmonet III, Sensormedics, Bilthoven, the Netherlands) with reference values of QUANJER et al. [21] was used. Patients were given a personal bests PEF meter (Health Scan Products Inc., Cedar Grove, NJ, USA) and were instructed in its correct use. They completed a general (demographic variables, morbidity) questionnaire and the Asthma Quality of Life Questionnaire (AQLQ) [22]. All patients received a 2-week diary in which to register their asthma symptoms (both day and night), medication use, and twice daily PEF (morning and evening), before using a bronchodilator. During the second visit, PC20 histamine was determined by applying the dosimeter method [19], and PEF meter use was optimized. The inhalation technique was assessed and corrected as needed. In addition, patients were provided with videotaped instructions for the correct use of their inhaler.

The personal best peak flow value (PBV) was the highest morning prebronchodilator PEF measurement as recorded in the 2-week diary by the stable patients, and in the diary kept for 4 weeks by the unstable patients, who were instructed to double their dose of inhaled steroids during the second 2 weeks.

Within 6 weeks of their first visit, all subjects were educated by a specially trained asthma nurse in three consecutive weekly sessions each lasting $90 \mathrm{~min}$, in groups of $5-10$ patients. Partners of the patients were also invited to attend. The educational programme was developed by the present group to suit the circumstances of Dutch patients with asthma. Its effectiveness was successfully evaluated in a pilot study including 24 adults with asthma [23, 24]. Patients were given a short explanation on the pathophysiology of asthma, the role of medication and side effects, allergic and nonallergic triggers, and symptoms indicating an impending exacerbation. They were encouraged to ask questions and discuss personal matters related to their disease. All patients were provided with two booklets on asthma $[25,26]$. Those belonging to group $\mathrm{S}$ received instructions about self-treatment of exacerbations during the third session, while patients belonging to group $\mathrm{C}$ did not. Specifically, group $\mathrm{S}$ was told to measure PEF weekly on a fixed day and at any time asthma symptoms worsened. They were provided with a 4-zone ("green", "yellow", "red", and "black") selftreatment plan, based on symptoms and morning prebronchodilator PEF, as detailed in table 1 [10]. To avoid overdosing, doubling of the dose of inhaled steroids was only recommended if PEF was $<80 \%$ of PBV on two consecutive mornings. If a patient was still in the "yellow" zone after 2 weeks use of a doubled dose of inhaled steroids, or still in the "red" zone after 1 week of prednisolone, they had to contact their physician.

At 4, 8, 12, 18, and 24 months after the start of the educational programme, participants completed the same 2-week diary, and carried out prebronchodilator spirometry at the same time of day as at the baseline assessment. They also repeated the AQLQ.

During the study period, the regular follow-up visits with the patient's own chest physician continued. Changes in maintenance therapy were permitted, if the patient or physician felt this was necessary. All patients were asked to call the outpatient clinic or 
Table 1. - Self-treatment plan

\begin{tabular}{llll}
\hline Step & Peak flow & \multicolumn{1}{c}{ Symptoms } & Action \\
\hline 1 (green zone) & $\begin{array}{l}80-100 \% \mathrm{PBV} \\
60-80 \% \mathrm{PBV}\end{array}$ & $\begin{array}{l}\text { No/intermittent/few } \\
\text { Increased cough/wheezing/ } \\
\text { shortness of breath } \\
\text { Nearly continuous shortness } \\
\text { of breath and/or poor response } \\
\text { to bronchodilator therapy }\end{array}$ & $\begin{array}{c}\text { Continue maintenance treatment } \\
\text { Double the dose of inhaled steroids } \\
\text { for } 2 \text { weeks } \\
\text { Prednisolone } 30 \mathrm{mg} \cdot \mathrm{day}{ }^{-1} \text { for } 7 \mathrm{days}\end{array}$ \\
$\begin{array}{l}50-60 \% \mathrm{PBV} \\
\text { (black zone) }\end{array}$ & $<50 \% \mathrm{PBV}$ & $\begin{array}{c}\text { Call/visit physician/emergency room } \\
\text { promptly }\end{array}$ \\
\hline
\end{tabular}

PBV: personal best value. At all stages, take inhaled $\mathrm{B}_{2}$-agonists for relief of symptoms.

emergency room, and not their general practitioner (GP), on a $24-\mathrm{h} \cdot \mathrm{day}^{-1}$ basis, for any incident related to their asthma. By reviewing the medical charts, data regarding the number of outpatient consultations and the number of hospitalizations were collected for the 1 - and 2-yr follow-up period, as well as for the 12 months prior to enrolment.

\section{Clinical outcome measures}

Clinical outcome measures were: a) pulmonary function at baseline and at 4, 8, 12, 18, and 24 months after entry: prebronchodilator FEV 1 ( $\%$ predicted) and from the 2-week diaries mean morning prebronchodilator $\mathrm{PEF}$ and mean diurnal $\mathrm{PEF}$ variability ((PEFevening-PEFmorning) $/ 1 / 2$ (PEF evening + PEFmorning $)$ $\times 100 \%$ ) [27] together with PC20 histamine at baseline and at 12 months. b) Asthma morbidity parameters: frequency of exacerbations, i.e. $\geqslant 2$ consecutive mornings with a PEF $<80 \%$ PBV during a two-week diary period, at baseline and at 4, 8, 12, 18, and 24 months; use of health care facilities in the year prior to, and the first and second year after the intervention: number of outpatient visits, hospitalizations, and hospital days.

\section{Patients' perspective outcome measures}

These outcome measures were: a) scores from the AQLQ at baseline and at 4, 8, 12, 18, and 24 months. This questionnaire is a disease-specific, 32-item instrument designed specifically for use in clinical trials. Four domains are distinguished: activity limitations, symptoms, emotions, and exposure to environmental stimuli. Patients rate the impairments they have experienced during the previous 14 days and respond to each item on a 7 -point scale $(1=$ maximal impairment, $7=$ no impairment). A difference in score of $\geqslant 0.5$ is considered clinically important for overall quality of life and for each of the individual domains [22]. b) Asthma symptoms: the percentage of symptom-free days and nights, derived from the 2-week diaries at baseline and at 4, 8, 12, 18 and 24 months. c) Perceived control of asthma and self-confidence regarding asthma computed from the evaluation form at 12 months, which asked whether or not there was better perceived control of asthma and whether self-confidence regarding asthma had increased (a 5-point scale $(1=$ no increase in selfconfidence, $5=$ much increase in self-confidence).

\section{Statistical analysis}

Analyses of repeated measurements were performed using Proc Mixed from SAS (SAS Institute Inc., Cary, NC, USA). When appropriate, pairwise comparisons were adjusted according to Tukey-Kramer. Ninety-five per cent confidence intervals $(95 \mathrm{CI})$ are presented. Before-after comparisons within patients were performed with the paired t-test. To achieve normally distributed data for $\mathrm{PC}_{20}$ values they were ${ }^{2} \log 10$ transformed. Between-group differences were analysed with the unpaired t-test. Differences in proportions were tested using the Chi-squared test and before-after changes in proportions were assessed by McNemar's test.

\section{Results}

\section{Subjects}

The number of patients randomized into group $\mathrm{S}$ was 123, while group C consisted of 122 patients. Characteristics of 1-yr and 2-yr follow-up patients are presented in table 2. The groups were comparable in their demographic and clinical features. The difference in gender distribution was not significant $(p=0.22)$. During the first 12-month study period six patients (three in each group) were lost to follow-up and one patient in group $\mathrm{S}$ died of a fall at home. After the first year of follow-up, the mean daily prescribed dose of inhaled steroids for both groups was unchanged. Of the remaining 238 patients, 174 continued for a second year of follow-up. In comparison with the first year, patients continuing in the second year were slightly, but insignificantly older at baseline. Nevertheless, the difference in mean age at baseline between the dropout group and the continuing group was $-6.6 \mathrm{yr}$ (95 CI $-9.8-3.4)$. Thus, the dropouts were significantly younger. In the second year, one patient in group $\mathrm{C}$ died of a cardiac arrest.

\section{Pulmonary function}

Relative to baseline values, both groups showed significant changes in PEF variability and PC20 
Table 2. - Baseline characteristics at the start of the first and second year of follow-up, for patients in the self-treatment (S) and control (C) group

\begin{tabular}{|c|c|c|c|c|}
\hline & \multicolumn{2}{|c|}{ First year } & \multicolumn{2}{|c|}{ Second year } \\
\hline & Group S & Group C & Group S & Group C \\
\hline Subjects $n$ & 123 & 122 & 84 & 90 \\
\hline Sex M:F & $51: 72$ & $60: 62$ & $36: 48$ & $44: 46$ \\
\hline \multirow{2}{*}{\multicolumn{5}{|c|}{ Education $\%$}} \\
\hline & & & & \\
\hline Low & 38.0 & 32.0 & 38.6 & 33.3 \\
\hline Medium & 35.5 & 41.0 & 39.7 & 37.8 \\
\hline High & 26.5 & 27.0 & 21.7 & 28.9 \\
\hline Mean duration of asthma yrs & $21.5 \pm 15.4$ & $18.4 \pm 14.2$ & $22.3 \pm 15.6$ & $16.8 \pm 13.5$ \\
\hline Skin prick test $\%$ positive & 67.5 & 67.5 & 64.3 & 65.9 \\
\hline \multicolumn{5}{|l|}{ Smoking \% } \\
\hline Nonsmokers & 54.4 & 51.7 & 58.3 & 51.1 \\
\hline Ex-smokers & 35.8 & 35.2 & 35.7 & 35.6 \\
\hline Smokers & 9.8 & 13.1 & 6.0 & 13.3 \\
\hline Inhaled steroids $\mu \mathrm{g} \cdot \mathrm{day}^{-1}$, MDI equivalent* & $617 \pm 443$ & $561 \pm 341$ & $616 \pm 469$ & $537 \pm 313$ \\
\hline FEV1 $\%$ pred & $76.0 \pm 20.0$ & $76.9 \pm 20.1$ & $75.7 \pm 21.8$ & $75.6 \pm 20.7$ \\
\hline Morning PEF $\mathrm{L} \cdot \mathrm{min}^{-1}$ & $381 \pm 113$ & $389 \pm 108$ & $378 \pm 120$ & $381 \pm 103$ \\
\hline
\end{tabular}

Data are presented as mean \pm SD or $\%$. *: The dose of inhaled steroids in dry powder inhalers was considered equipotent to half the dose in metered dose inhalers (MDI). Fluticasone propionate was considered twice as potent as beclomethasone dipropionate and budesonide. FEV1: forced expiratory volume in one second; PEF: peak expiratory flow.

histamine. Mean decreases in PEF variability over the entire follow-up period (measured at $4,8,12,18$, and 24 months), compared to baseline, were $32 \%$ in group $\mathrm{S}$ and $29 \%$ in group C (fig. 1). Complete data on PC20 histamine at baseline and at $1 \mathrm{yr}$ of follow-up were available for 80 patients in group $\mathrm{S}$, and 84 patients in group C. In both groups, $\mathrm{PC} 20$ histamine increased significantly (table 3 ). Group $\mathrm{C}$ showed a small but significant mean increase in FEV1 \% pred over the entire follow-up period, of $3 \%$, while in group $\mathrm{S}$ morning PEF increased significantly by $2 \%$. No significant differences were found between the groups in any of the pulmonary function variables.

\section{Asthma quality of life}

The scores for overall quality of life (qol) for both groups increased by a mean of $7 \%$ over the entire

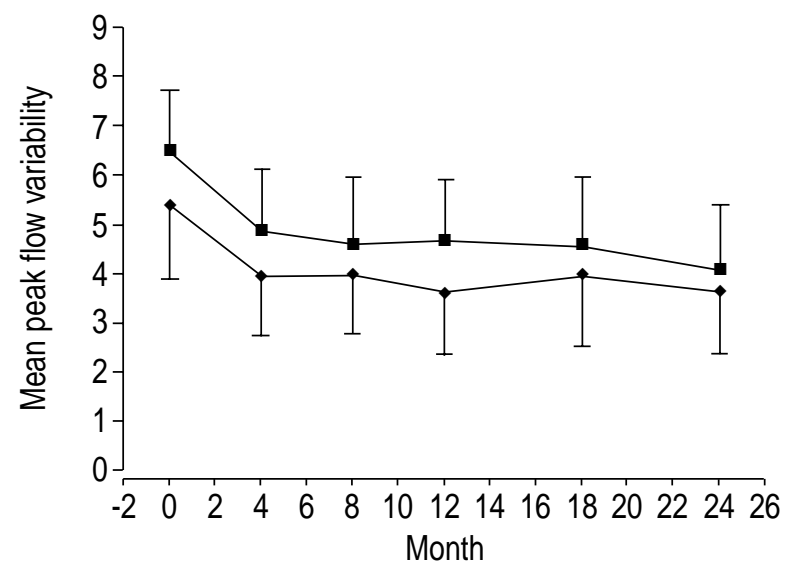

Fig. 1. - Mean values of peak expiratory flow variability from visit 1 to 6 for patients in the self-treatment (S) and control group (C). Vertical bars indicate $95 \%$ confidence intervals. group $\mathrm{S} ; \mathbf{\square}$ : group $\mathrm{C}$. follow-up period (measured at 4, 8, 12, 18, and 24 months), in comparison with baseline (fig. 2). Each of the four individual domains also showed significant improvements $(p<0.001)$. The domain related to activity limitations and exposure to environmental stimuli showed the most substantial changes. Relative to baseline values, scores for the activities domain increased by a mean of $9 \%$ in both groups. The scores for the domain with regard to exposure to environmental stimuli improved by $9 \%$ and $8 \%$ for groups $\mathrm{S}$ and $\mathrm{C}$, respectively. The symptom-related scores improved by $6 \%$ and $7 \%$ for groups $\mathrm{S}$ and $\mathrm{C}$ respectively, while both groups showed an improvement of $5 \%$ in scores related to the emotions domain. Neither the overall score or the scores in the individual domains showed significant differences between the groups.

\section{Asthma morbidity parameters}

During the 2-yr follow-up, the frequency of exacerbations decreased by $2 \%(95 \mathrm{CI}-11-7)$ in patients of group S, and increased by 5\% (95 CI -4-14) in patients of group C (fig. 3). The difference of $7 \%$ between the groups was not significant $(95 \mathrm{CI}-2-16)$. In the two

Table 3. - Provocative concentration ( $\mathrm{PC}_{20}$ ) of histamine causing a $20 \%$ fall in forced expiratory volume in one second data of self-treatment (S) and control (C) groups during one year

\begin{tabular}{lcc}
\hline & Group S & Group C \\
\hline PC20 histamine $\mathrm{mg} \cdot \mathrm{mL}^{-1}$ & & \\
Baseline & $4.75 \pm 4.7$ & $3.55 \pm 4.1$ \\
12 months & $7.29 \pm 7.6$ & $5.88 \pm 7.3$ \\
Mean change from baseline & $2.54(1.0-4.0)$ & $2.33(0.9-3.7)$ \\
\hline
\end{tabular}

Data are presented as mean \pm SD or mean $(95 \%$ confidence interval). 


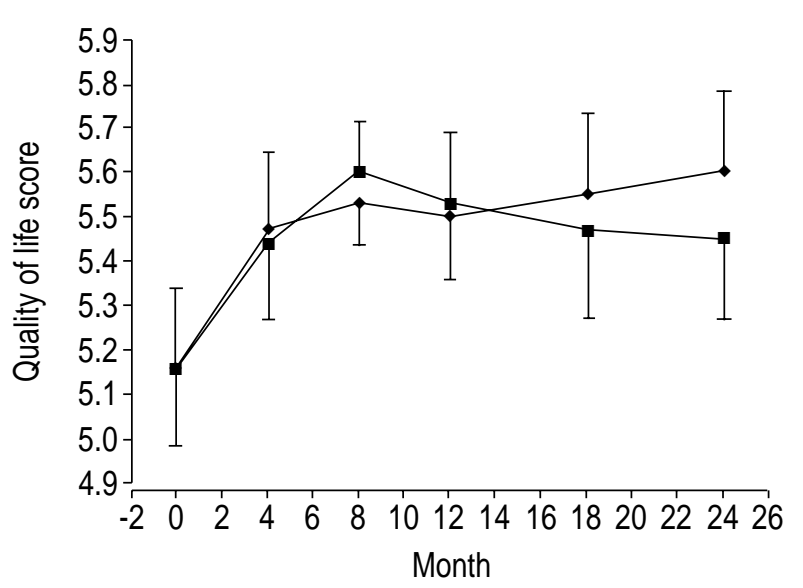

Fig. 2. - Mean values of overall asthma quality of life scores from visit 1 to 6 for patients in the self-treatment (S) and control group $(\mathrm{C})$. Scores are made up of 32 items, each ranging 1-7. A higher score represents a better quality of life. Vertical bars indicate $95 \%$ confidence intervals. $\bullet$ : group $\mathrm{S}$; $\mathbf{\square}$ : group $\mathrm{C}$.

weeks immediately prior to the self-management programme, 31 patients in group $\mathrm{S}$ experienced an exacerbation and of those, $6(21 \%)$ doubled their dose of inhaled steroids. During the last 2 weeks of the first year of follow-up, 24 patients in group $\mathrm{S}$ had an exacerbation and of those patients, $8(33 \%)$ doubled their inhaled steroids. Due to the low number of patients with an exacerbation, this increase was not statistically significant. There was a significant decrease in the total number of outpatient visits in both groups. Mean changes in number of outpatient visits per patient per year were $25 \%$ and $18 \%$ for groups $\mathrm{S}$ and $\mathrm{C}$ respectively. The mean number of outpatient visits, either scheduled or unscheduled decreased from an average of 3.4 in both the intervention and control group in the year prior to the study, to 2.6 and 2.8 in intervention and control group, respectively, in the first year of follow-up and remained at this level during the second year of follow-up. The difference between the

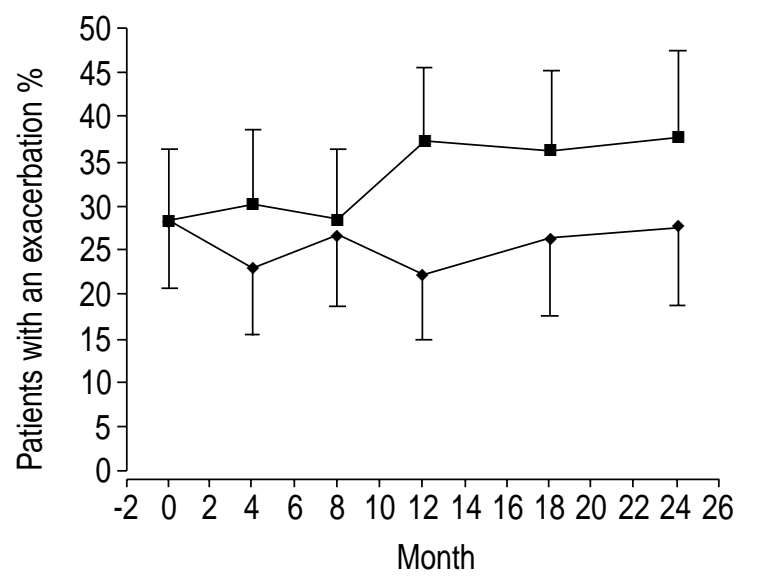

Fig. 3. - Percentage of patients with an exacerbation (defined as self-recorded PEFs $<80 \%$ of the personal best value during $\geqslant 2$ consecutive mornings during a 2-week period) from visit 1 to 6 for patients in the self-treatment (S) and control (C) groups. Vertical bars indicate $95 \%$ confidence intervals. $\bullet$ : group $\mathrm{S}$; group $\mathrm{C}$. two groups was not significant. Telephone contacts were only registered for the first year of follow-up. The total number of telephone contacts increased significantly in both groups compared with the year prior to the intervention. For group $\mathrm{S}$ it increased from an average of 0.16 calls per patient in the year before the study, to 0.39 calls in the first year of follow-up (increase $0.23 ; 95 \%$ CI $0.02-0.43$ ). For group C it increased from $0.24-0.58$ (difference $0.34 ; 95 \%$ CI 0.15-0.55). Again, the difference between the two groups was not significant. Hospital admissions for asthma were rare (fig. 4). Both the within-group differences and the between-group differences were not significant.

\section{Asthma symptoms}

After 2 yrs, no within-group or between-group differences were found in the percentage of symptomfree days and nights (fig. 5).

\section{Perceived control of asthma and self-confidence regarding asthma}

The majority of patients in both groups perceived better control of asthma at 12 months than before the intervention. The percentage of patients in group $S$ indicating this improvement was significantly higher than in group C. Perceived self-confidence regarding asthma increased in both groups, with group $\mathrm{S}$ scoring significantly better (table 4).

\section{Discussion}

This study failed to show additional benefit in terms of clinical outcome measures from adding selftreatment guidelines (action plan) to a self-management programme. This might be due to the fact that these patients with stable, moderate to severe asthma, were very well-controlled and already on relatively high doses of inhaled corticosteroids, and had $24 \mathrm{~h}$ access to

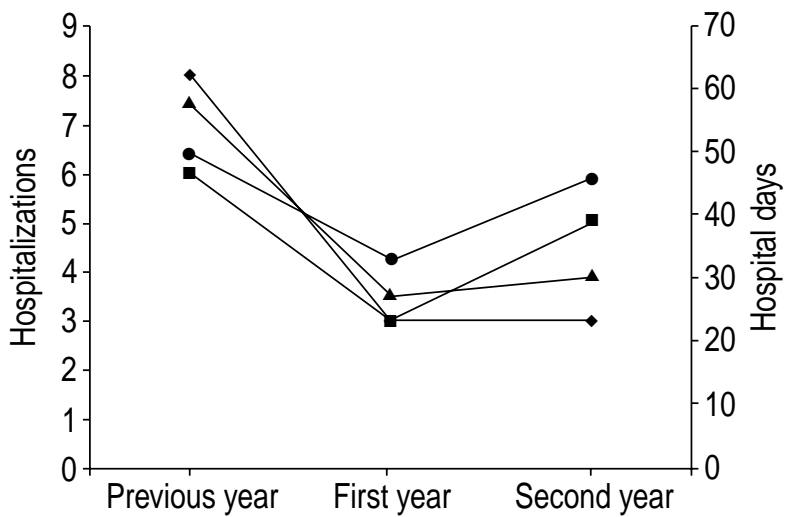

Fig. 4. - Total number of hospitalizations and total hospital days for asthma in the year prior to, and the first and second year after the start of the study for patients in the self-treatment (S) and control (C) groups. $\bullet$ : group S hospitilizations; group $\mathrm{C}$ hospitilizations; $\boldsymbol{\Delta}$ : group $\mathrm{S}$ hospital days; $\bullet$ : group $\mathrm{C}$ hospital days. 


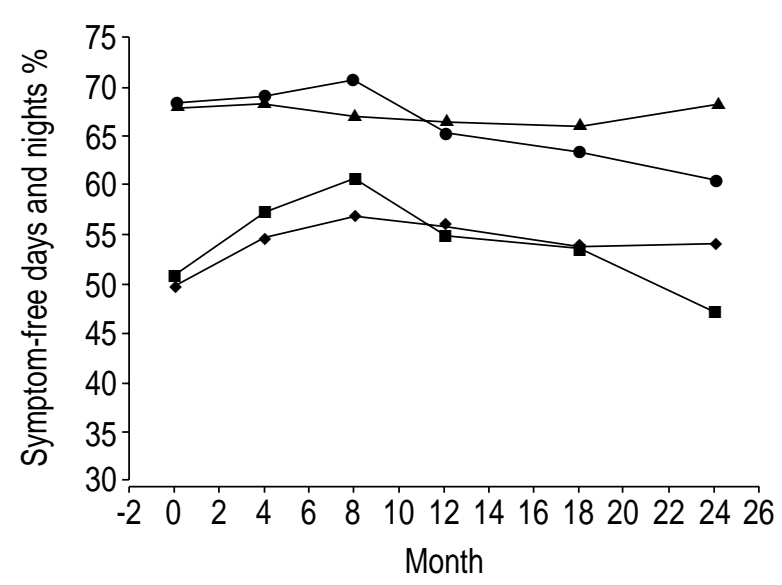

Fig. 5. - Mean percentage of symptom-free days and nights from visit 1 to 6 for patients in the self-treatment $(S)$ and control (C) groups. $\diamond$ : group $\mathrm{S}$ symptom-free days; $\mathbf{\square}$ : group $\mathrm{C}$ symptom-free days; $\boldsymbol{\Delta}$ : group $\mathrm{S}$ symptom-free nights; $\bullet$ : group $\mathrm{C}$ symptom-free nights.

advice and management of their disease. The only differences observed between group $\mathrm{S}$ and group $\mathrm{C}$ were better perceived control of asthma, and more self-confidence regarding asthma for patients who had received the self-treatment guidelines (action plan) after 1 yr.

After 2 yrs, all patients showed favourable changes in PEF variability, asthma-related quality of life and number of outpatient visits, and no between-group differences were seen. The improvements in morning $\mathrm{PEF}$ in group $\mathrm{S}$ and $\mathrm{FEV} 1$ in group $\mathrm{C}$ were too small to be clinically important. In both groups, no changes were seen in frequency of exacerbations, number of hospitalizations, and symptom-free days and nights, and again no differences between group $\mathrm{S}$ and $\mathrm{C}$ were found. Improvements in health-related outcomes persisted throughout the whole study. In addition, neither group showed significant deteriorations after 2 yrs. This trend was particularly clear in group S. Thus, guidelines for self-treatment of exacerbations seem to be safe.

Originally, this trial was designed with a follow-up of $1 \mathrm{yr}$. After eight months of follow-up it was decided to extend the study for another year because the follow-up measurements at 4 and 8 months showed an almost linear improvement in most outcome parameters. As it was unclear if this trend would continue or not, aborting the study at too early a stage (12 months) seemed unwise. At the end of the first year, all patients were asked to participate for a second year. As mentioned in the results, $27 \%$ refused. Such a dropout rate could cause selection bias. To investigate whether this had in fact happened, results of the outcome measures at 12 months (at time of dropout) were compared of those subjects who had stopped, and those who had continued, using unpaired t-tests. It appeared from this analysis that patients who had stopped did not differ significantly from the group that continued regarding the main outcome measures. Patients who had stopped were significantly younger, but this difference in age did not affect the internal validity of this study.
Although at the beginning of the study all patients were in a stable phase of their disease, most improvements, even in PEF variability (which was already very low in both groups at the beginning of the study) were seen in the first 4 or 8 months of the study. Afterwards, improvements persisted or only slight changes were observed in both groups. Since optimization of the pharmacological treatment appears to be the main determinant of asthma-related morbidity [5, 14], better compliance with inhaled medication, and/or better inhalation technique, are the probable causes of the improvements in the first 4 to 8 months. In a pilot study $(n=21)$ of the self-management programme, compliance with inhaled medication was assessed by using electronic inhalation devices. At baseline, mean compliance (number of actual inhalations/number of prescribed inhalations) was $83 \%$ and improved by $12 \%$ (95 CI 3 -21) [23]. In 166 patients, using the same inhaler throughout the present study, inhalation technique was assessed. At baseline only $72 \%$ of patients performed all essential inhalation manoeuvres correctly, which increased to $80 \% 1 \mathrm{yr}$ after instruction [28]. These two studies offer some evidence that improvements in compliance and/or inhalation technique might, in part, be responsible for the improvements seen in the first 4 or 8 months of the study. Particularly in group $\mathrm{S}$, these improvements persisted throughout the rest of the study. This is possibly due to the self-treatment guidelines, although in the pilot study [23] of the self-management programme among 21 asthma patients it appeared that patients only partially complied with the self-treatment guidelines. Of the 10 (out of 21) patients whose PEF fell $<80 \%$, or who perceived more symptoms, only three actually doubled their dose of inhaled steroids; four patients were willing to increase, but not double; and three did not alter their behaviour at all. Four out of five patients whose PEF fell $<60 \%$ of their PBV started a course of oral prednisolone. However, data on prednisolone use were based on self-report, so they have to be interpreted with caution.

To increase compliance with the self-treatment guidelines in the present study, more attention was paid on discussing the side effects of inhaled and oral steroids than in the pilot study. Moreover, the importance of following the self-treatment guidelines was thoroughly discussed. The authors think that

Table 4. - Perceived control of asthma and self-confidence regarding asthma in the self-treatment $(S)$ and control (C) groups after one year follow-up

\begin{tabular}{lccc}
\hline & Group S & Group C & p-value \\
\hline $\begin{array}{l}\text { Subjects n } \\
\text { Perceived control of }\end{array}$ & 118 & 118 & \\
$\quad \begin{array}{l}\text { asthma* } \\
\text { Perceived self-confidence }\end{array}$ & $3.76 \pm 1.06$ & $3.41 \pm 1.23$ & 0.018 \\
\hline
\end{tabular}

*: percentage of patients answering "yes" to the question: "is your asthma better controlled than before the intervention?" (Chi-squared test). \#: Data are mean \pm SD scores for answers to the question: "do you have more self-confidence regarding your asthma than before the intervention?" (range 1-5; $1=$ no increase and $5=$ much increase) (t-test). 
patients in the present study were more willing to comply with the guidelines than patients in the pilot study, although this was not measured. However, it was not until the third educational session that patients in group $\mathrm{S}$ received instructions regarding the selftreatment guidelines. Probably, earlier instruction (during the first session) might be more effective in increasing compliance with the self-treatment guidelines.

For several reasons, this study cannot be compared with most studies regarding self-management in adult asthmatics. Firstly, only adults with stable, moderate to severe asthma, and who were already on high doses of inhaled corticosteroids were included. Secondly, all patients received similar education and training in three group sessions (90 min per session), while group $\mathrm{S}$ additionally received a self-treatment plan. Thus, the only difference between the groups is the self-treatment guidelines. Thirdly, the follow-up of this study was $2 \mathrm{yrs}$, which is much longer than follow-up periods in most other studies. Only three studies are comparable with the present study with respect to one of the last two aspects. With respect to the long-term effects of a self-management programme including self-treatment guidelines, only one study has been published. The study by D'SouzA et al. assessed the effectiveness of an asthma self-management programme 2 yrs after the self-management programme, which lasted for six months [29]. They found a long-term reduction in asthma morbidity and requirement for acute medical services. Unfortunately, the study of D'Souza et al. [29] lacked a control group. JonEs et al. [30] published a study in which, similar to this study, the only difference between the groups was the use of home peak flowbased self-management plan. They found no betweengroup differences in patients with mild asthma in terms of lung function, symptoms, quality of life, and prescribing costs. However, in the study of JonEs et al. [30] self-management teaching lasted for a median of $14 \mathrm{~min}$, while in this study, patients were educated for at least $270 \mathrm{~min}$. In a study by CowIE et al. [15], 150 patients who had all required urgent treatment for their asthma within the previous 12 months, received evaluation and education for asthma before being randomly allocated to receive either no action plan, a symptom-based action plan, or a peak flow-based action plan. Six months after enrolment a highly noticeable reduction in emergency department visits for asthma was observed only in the peak flow-based action plan group, although all three groups experienced improvement in their asthma control. At six months after entry, no significant difference with regard to the daily dose of inhaled steroids was noted in the subjects as a whole or among each of the three study groups. However, from data presented in their paper it appeared that $31(22 \%)$ of the 139 subjects did not use inhaled steroids at enrolment, whereas during the study each action plan included baseline therapy with inhaled steroids. This means that these patients were prescribed inhaled steroids for the first time, which can partly explain the improvements found.

Similar to other studies $[9,12,30,31]$, minimal improvements in FEV1 and morning PEF in both groups was found. However, two studies found clinically important improvements in FEV1 \% pred and PEF. Ignacio-Garcia and Gonzalez-Santos [11] reported a significant increase in both FEV1 \% pred $(75-80 \%)$ and morning PEF $\left(370-401 \mathrm{~L} \cdot \mathrm{min}^{-1}\right)$ in the self-treatment group. TURNER et al. [16] found clinically relevant improvements in FEV1 \% pred $(78.1-83.0 \%$ in the peak flow meter (PFM) self-treatment group and $78.8-86.1 \%$ in the symptom self-treatment group) and PEF $\left(368-406 \mathrm{~L} \cdot \mathrm{min}^{-1}\right.$ and $370-410 \mathrm{~L} \cdot \mathrm{min}^{-1}$, respectively). It should be noted that patients in the IGNACIOGarcia and Gonzalez-Santos [11] study showed a great PEF variability at first assessment $(>30 \%)$, indicating that the patients were not stable at enrolment. This could explain the difference between their study and the present study regarding lung function outcomes, since the patients in this study were stable at enrolment. Whether patients in the study of TURNER et al. [16] were stable at enrolment is not described, so it is difficult to explain the differences compared with the present findings. However, it should be noted that 14 (of 44) and 12 (of 48) patients in the PEF and the symptom groups respectively, were prescribed inhaled steroids for the first time. These steroid-naive patients had a higher baseline FEV1 (3.07 versus $2.76 \mathrm{~L}$, $\mathrm{p}=0.116)$ and had a greater increase in FEV1 $(0.472$ versus $0.194 \mathrm{~L}, \mathrm{p}=0.046$ ) after one month of inhaled steroid use.

The finding of favourable changes in PEF variability and $\mathrm{PC}_{20}$ histamine in both groups indicates less bronchial hyperresponsiveness at 12 months after the intervention than at baseline. This is consistent with TURNER et al. [16], who found a greater than two-fold increase in PC20 metacholine in both the PFM and symptom group after six months. This result could mean that the severity of asthma in the present patients diminished during the course of the study [32]. These data are quite remarkable because at baseline the patients were very stable and their daily dosage of inhaled steroids remained unchanged at a high level after $1 \mathrm{yr}$. Better compliance with the prescribed medication or better inhalation technique, as a result of the self-management programme, could be an explanation.

The reason why improvements in qol $(7 \%$ increase in both groups) were low and did not reach clinically important values might be that only patients who were well-controlled, very stable and who were all receiving relatively high doses of inhaled steroids at enrolment were included. These small improvements are consistent with JoNEs et al. [30] and LAHDENSUO et al. [12], both using different asthma-specific quality of life questionnaires. The AQLQ was also used in two other studies. Boulet et al. [33] used the AQLQ in a retrospective case-control study. Also in this study, improvements in patients (in the intervention group) did not reach a clinically important value (0.43). On the other hand, TURNER et al. [16] found in both the PFM and symptom groups clinically important improvements in qol of $>1.0$ unit after six months.

In contrast with the present study, IGNACIO-GARCIA and GonZalez-SAnTos [11] found fewer exacerbations in both the intervention and control group, which can be explained by the higher daily dosage of inhaled steroids at the end of their study. 
In both groups a decrease in the number of outpatient visits for asthma was found. This result is highly noticeable, since patients were asked to call the outpatient clinic or emergency room, and not their general practitioner, for any incident related to their asthma. The failure of this study to detect any differences in the decreased number of outpatient visits during the follow-up period between the intervention and control patients is not consistent with the findings of LAHDENSUO et al., [12] who reported a decline in the intervention group only. In contrast to that study, the present control group was educated in self-management skills, which could explain the differences in the results.

It was found that the number of hospital admissions was already low in the year prior to the study, and that no significant changes were observed during the 24 months of follow-up. This finding is not consistent with those of three other studies [9, 11, 34] that reported a significant decrease in this outcome parameter. The differences in these findings could be explained by the inclusion of unstable patients in the other studies. In a study by Côté et al. [14] a decrease in hospital admissions in both intervention and control groups was found. Although stable patients were included, an explanation for the difference could be that, in their study, patients were rigorously optimized regarding their asthma therapy, in contrast to the patients in this study.

Few other controlled studies regarding PEF-guided self-treatment guidelines have reported data about daily symptoms. The finding of no change in symptoms in the studies of Jones et al. [30], Yoon et al. [9], and in the Grampian Asthma Study of Integrated Care [31] is consistent with the present results of no change in symptom-free days at 24 months of follow-up.

Important favourable outcomes of intervention were the perceived better control of asthma and the improved self-confidence regarding asthma in the majority of patients in both groups, but with significantly better scores for the intervention group at 12 months after the start of the self-management programme. This finding shows that an educational programme for self-management that includes selftreatment guidelines markedly diminished the feeling of "not being in control", as well as the emotions associated with uncertainty and dependency [35].

In two recent reviews it was found that asthma education programmes (with or without guidelines for self-treatment of exacerbations) vary widely in their methods and content [36, 37]. This makes it difficult to identify the most effective components of these programmes. To overcome this problem a more systematic description of asthma self-management programmes should be promoted [37]. Furthermore, the only difference between the intervention and control group should be one specific component of the selfmanagement programme [38]. In the present study, the only difference between the intervention and control group was the self-treatment guidelines. Although both groups showed improvement in health-related outcomes, the only difference between the two groups was a significantly better score at 12 months in perceived better control of asthma and improved self-confidence regarding asthma in the intervention group. To investigate which part of the self-management programme was most effective, more research is needed.

\section{References}

1. Sly RM. Increases in death from asthma. Ann Allergy 1984; 53: 20-25.

2. Burney PGJ. Asthma mortality in England and Wales: evidence for a further increase, 1974-84. Lancet 1986; ii: $323-326$.

3. Mitchell EA. International trends in hospital admission rate for asthma. Arch Dis Child 1985; 60: $376-378$.

4. Sears MR. Epidemiology. In: Barnes PJ, Rodger IW, Thomson NC, eds. Asthma: Basic Mechanisms and Clinical Management. London: Academic Press Limited, 1992; pp. $1-19$.

5. National Heart Lung and Blood Institute. Global strategy for asthma management and prevention. NHLBI/WHO Workshop Report. Bethesda, Maryland 20892, USA: National Institutes of Health, 1995.

6. British Thoracic Society. Guidelines for management of asthma in adults: I-chronic persistent asthma. BMJ 1990; 301: 651-653.

7. Charlton I, Charlton G, Broomfield J, Mullee MA. Evaluation of peak flow and symptoms only self management plans for control of asthma in general practice. BMJ 1990; 301: 1355-1359.

8. Mühlhauser I, Richter B, Kraut D, Weske G, Worth $\mathrm{H}$, Berger M. Evaluation of structured treatment and teaching programme on asthma. J Intern Med 1991; 230: $157-164$.

9. Yoon R, McKenzie DK, Bauman AE, Miles DA. Controlled trial evaluation of an asthma education programme for adults. Thorax 1993; 48: $1110-1116$.

10. D'Souza W, Crane J, Burgess C, et al. Communitybased asthma care: trial of a "credit card" asthma self-management plan. Eur Respir $J$ 1994; 7 $1260-1265$.

11. Ignacio-Garcia JM, Gonzalez-Santos P. Asthma selfmanagement education program by home monitoring of peak expiratory flow. Am J Respir Crit Care Med 1995; 151: $353-359$.

12. Lahdensuo A, Haahtela $\mathrm{T}$, Herrala $\mathrm{J}$, et al. Randomised comparison of guided self management and traditional treatment of asthma over one year. BMJ 1996; 312: 748 - 752 .

13. D'Souza W, Burgess C, Ayson M, Crane J, Pearce N, Beasley R. Trial of a "credit card" asthma selfmanagement plan in a high-risk group of patients with asthma. J Allergy Clin Immunol 1996; 97: 10851092.

14. Côté J, Cartier A, Robichaud P, et al. Influence on asthma morbidity of asthma education programs based on self-management plans following treatment optimization. Am J Respir Crit Care Med 1997; 155: $1509-1514$.

15. Cowie RL, Revitt SG, Underwood MF, Field SK. The effect of a peak flow-based action plan in the prevention of exacerbations of asthma. Chest 1997; 112: $1534-1538$.

16. Turner MO, Taylor DW, Bennett R, FitzGerald JM. A randomized trial comparing peak expiratory flow 
and symptom self-management plans for patients with asthma attending a primary care clinic. Am J Respir Crit Care Med 1998; 157: 540-566.

17. Gibson PG, Coughlan J, Wilson AJ, et al. Selfmanagement education and regular practitioner review for adults with asthma (Cochrane Review). The Cochrane Library, Issue 1. 2000. Oxford: Update Software.

18. Quanjer PH, Tammeling GJ, Cotes JE, Pedersen OF, Peslin R, Yernault JC. Lung volumes and forced ventilatory flows. Official statement of the European Respiratory Society. Eur Respir J 1993; 6: 5-40.

19. Sterk PJ, Fabbri LM, Quanjer PH, et al. Airway responsiveness. Standardized challenge testing with pharmacological, physical and sensitizin stimuli in adults. Official statement of the European Respiratory Society. Eur Respir J 1993; 6: 53-83.

20. The Committee on Skin Test Standardization of the Netherlands Society of Allergology. Report on skin test standardization. Clinical Allergy 1988; 6: $305-$ 310.

21. Quanjer PH, Dalhuijsen A, van Zomeren BC. Summary equations of reference values. Bull Europ Physiopathol Respir 1983; 19: 45-51.

22. Juniper EF, Guyatt GH, Ferrie PJ, Griffith LE. Measuring quality of life in asthma. Am Rev Respir Dis 1993; 147: $832-838$

23. Van der Palen J, Klein JJ, Rovers MM. Compliance with inhaled medication and self-treatment guidelines following a self-management programme in adult asthmatics. Eur Respir J 1997; 10: 652-657.

24. Klein JJ, Van der Palen J, Van den Hof S, Rovers MM. Self-treatment by adults during slow-onset exacerbations of asthma. Pat Educ Couns 1997; 32: S61 - S66.

25. Glaxo BV. Nederland. Gezond met astma. Zeist: Glaxo B.V. Nederland, 1995.

26. Van der Brink WTJ. 120 vragen over CARA. Utrecht: Het Spectrum B.V., 1995.

27. Quackenboss JJ, Lebowitz MD, Krzyzanowski M. The normal range of diurnal changes in peak expiratory flow rates. Relationship to symptoms and respiratory disease. Am Rev Respir Dis 1991; 143: $323-330$.
28. Van der Palen J, Klein JJ, Kerkhoff AH, van Herwaarden CL, Zielhuis GA, Seydel ER. Inhalation technique of 166 adult asthmatics prior to and following a self-management program. $J$ Asthma 1999; 36: $441-447$.

29. D'Souza WJ, Te KH, Fox C, et al. Long-term reduction in asthma morbidity following an asthma self-management programme. Eur Respir J 1998; 11: $611-616$.

30. Jones KP, Mullee MA, Middleton M, Chapman E, Holgate ST. Peak flow based asthma self-management: a randomised controlled study in general practice. Thorax 1995; 50: $851-857$.

31. Grampian Asthma Study of Integrated Care (GRASSIC). Effectiveness of routine self monitoring of peak flow in patients with asthma. BMJ 1994; 308: $564-567$.

32. Ryan G, Latimer KM, Dolovich J, Hargreave FE. Bronchial responsiveness to histamine: relationship to diurnal variation of peak flow rate, improvement after bronchodilator, and airway calibre. Thorax 1982; 37: 423-429.

33. Boulet LP, Boutin H, Côté J, Leblanc P, Laviolette M. Evaluation of an asthma self-management education program. J Asthma 1995; 32: 199-206.

34. Mayo PH, Richman J, Harris HW. Results of a program to reduce admissions for adult asthma. Ann Intern Med 1990; 112: 864-871.

35. Partridge MR. An introduction to a special issue of "Patient Education and Counseling" entitled "Self Management in Adults with Asthma". Pat Educ Couns 1997; 32: sl-s4.

36. Meijer RJ, Kerstjens HA, Postma DS. Comparison of guidelines and self-management plans in asthma. Eur Respir J 1997; 10: 1163-1172.

37. Sudre P, Jacquemet S, Uldry C, Perneger TV. Objectives, methods and content of patient education programmes for adults with asthma: systematic review of studies published between 1979 and 1998. Thorax 1999; 54: 681-687.

38. Van der Palen J, Klein JJ, Zielhuis GA, Van Herwaarden CLA. The role of self-treatment guidelines in self-management education for adult asthmatics. Respir Med 1998; 92: 668-675. 